\title{
Light-Driven Hydrogen Evolution Assisted by Covalent Organic Frameworks
}

\author{
Nuria Romero, Roger Bofill *(D), Laia Francàs, Jordi García-Antón (D) and Xavier Sala *(D) \\ Department of Chemistry, Universitat Autònoma de Barcelona, 08193 Bellaterra, Spain; \\ Nuria.Romero@uab.cat (N.R.); Laia.Francas@uab.cat (L.F.); Jordi.GarciaAnton@uab.es (J.G.-A.) \\ * Correspondence: Roger.Bofill@uab.cat (R.B.); Xavier.Sala@uab.cat (X.S.); Tel.: +34-93-581-2886 (R.B.); \\ +34-586-8295 (X.S.)
}

\begin{abstract}
Covalent organic frameworks (COFs) are crystalline porous organic polymers built from covalent organic blocks that can be photochemically active when incorporating organic semiconducting units, such as triazine rings or diacetylene bridges. The bandgap, charge separation capacity, porosity, wettability, and chemical stability of COFs can be tuned by properly choosing their constitutive building blocks, by extension of conjugation, by adjustment of the size and crystallinity of the pores, and by synthetic post-functionalization. This review focuses on the recent uses of COFs as photoactive platforms for the hydrogen evolution reaction (HER), in which usually metal nanoparticles (NPs) or metallic compounds (generally Pt-based) act as co-catalysts. The most promising COF-based photocatalytic HER systems will be discussed, and special emphasis will be placed on rationalizing their structure and light-harvesting properties in relation to their catalytic activity and stability under turnover conditions. Finally, the aspects that need to be improved in the coming years will be discussed, such as the degree of dispersibility in water, the global photocatalytic efficiency, and the robustness and stability of the hybrid systems, putting emphasis on both the COF and the metal co-catalyst.
\end{abstract}

Citation: Romero, N.; Bofill, R.;

Francàs, L.; García-Antón, J.; Sala, X. Light-Driven Hydrogen Evolution Assisted by Covalent Organic Frameworks. Catalysts 2021, 11, 754. https://doi.org/10.3390/catal11060754

Keywords: covalent organic framework; covalent triazine framework; photocatalysis; hydrogen evolution; metal nanoparticle; co-catalyst; Pt-doped COF; bandgap; charge separation; apparent quantum efficiency

Academic Editor: Víctor A. de la Peña O'Shea

Received: 1 June 2021

Accepted: 17 June 2021

Published: 21 June 2021

Publisher's Note: MDPI stays neutral with regard to jurisdictional claims in published maps and institutional affiliations.

\section{Introduction}

Covalent organic frameworks (COFs) are 2D or 3D low density crystalline porous materials with periodically ordered skeletons constituted by organic molecules linked through covalent bonds. They were first reported by Yaghi and collaborators in 2005 from condensation of benzenediboronic acid (BDBA) alone and in the presence of hexahydroxytriphenylene (HHTP) in a simple one-pot procedure at $120^{\circ} \mathrm{C}$, obtaining a boroxine $\mathrm{COF}$ (COF-1) and a boronate ester COF (COF-5), respectively [1]. Since then, there has been steady growth in the number of published works dealing with the synthesis, properties, and catalytic applications of COFs. In contrast to other porous organic polymers (POPs), $\mathrm{COF}$ are crystalline (long-range ordered) by definition. In fact, some authors consider POPs to be amorphous COFs, and classify COFs according to their type of long-range order (0D, 1D, 2D, and 3D COFs) [2]. The crystallinity of COFs is governed by their predesigned tailor-made structures, which involve a geometric combination of rigid monomers to guide the growth of polygonal structures [3]. On the other hand, the porosity of COFs is intrinsically linked to the geometry and topicity of the nodes and linkers selected. In fact, one can find COFs with regular pores of a single geometry (trigonal, tetragonal, rhombohedral, or hexagonal), with a mixture of two geometries (two different trigonal ones or hexagonal plus trigonal), or with irregular geometrical pores [3]. The formation of the pores is generally driven by intermolecular interactions, mainly $\pi$-stacking and hydrogen bonds [4], but new strategies using templates are being developed [5]. 
Semiconductors are materials able to harvest light that can be used to induce photochemical transformations, such as the hydrogen evolution reaction (HER), if they exhibit appropriate bandgaps. Under these conditions, electrons are excited from the valence band (VB) to the conduction band (CB) by photons with an energy greater than the bandgap, which are then used to reduce protons to $\mathrm{H}_{2}$. Historically, semiconductors used for HER photocatalysis have been CdS [6] and $\mathrm{Ag}_{3} \mathrm{PO}_{4}$ [7], absorbing in the visible region but containing expensive and polluting metals, or graphitic $\mathrm{C}_{3} \mathrm{~N}_{4}\left(\mathrm{~g}-\mathrm{C}_{3} \mathrm{~N}_{4}\right)$, which absorbs in the visible range although its bandgap tuning is constrained by its fixed structure [8]. In 2014, Lotsch et al. described for the first time the photocatalytic HER ability of a Pt-doped hydrazone-linked COF derived from 1,3,5-tris-(4-formyl-phenyl)triazine (TFPT-COF) [9]. Thanks to the visible-light-absorbing properties of the crystalline honeycomb-type planar organic scaffold, TFPT-COF can act as the photosensitizer, while Pt acts as the co-catalyst. Afterwards, a large amount of work has been done in this area because COFs show several advantages compared with commonly used semiconductors: (1) they are $100 \%$ organic, reducing the price of the photocatalyst; (2) they allow for the tuning of the bandgap by modifying the building blocks; (3) they are mostly obtained under mild reaction conditions (in contrast to $\mathrm{g}-\mathrm{C}_{3} \mathrm{~N}_{4}$ ); (4) they are highly porous and show a large exposed surface area that allows the light to pass through the material without substantial energy loss while offering high accessibility to electrolytes, sacrificial components, and co-catalysts; (5) they are usually stable within a large range of $\mathrm{pH}$ thanks to the covalent bonds between their building blocks, which is a key requisite for water splitting reactions; and (6) they are rigid, which enhances the excited state lifetime and allows for conjugation and stacking, which increase the charge mobility and prevent deactivation.

The authors do not pretend in this review to make a comprehensive list of all COFs used in the photocatalytic HER, since excellent reviews on this topic have been published recently and the readers can refer to them for more detailed information (see for example [2,10-17]), but to give a critical perspective of the strong points and the future goals to be achieved within this exciting research field. In addition, the authors have chosen to address this review exclusively to photocatalytically active COFs, and thus electrocatalysis studies are excluded. When comparing photocatalytic systems, the authors have been careful, as the given values of hydrogen formation rate $\left(\mu \mathrm{mol} \cdot \mathrm{h}^{-1}\right.$ or $\left.\mu \mathrm{mol} \cdot \mathrm{h}^{-1} \cdot \mathrm{g}^{-1}\right)$ often strongly depend on the light source (wavelength and intensity), reactor size, photocatalyst concentration, and the co-catalyst's nature and amount. Unfortunately, a benchmarking protocol has yet to be established. Therefore, this review will focus more on general trends than on numerical comparisons, although some quantitative figures will be given to give the reader an idea of the order of magnitude of photocatalytic HER activity. Furthermore, the COFs that have provided a breakthrough in the field because of their novelty and significant contribution to opening up new exciting opportunities will be described in special detail.

\section{Crucial Aspects Determining the Photocatalytic Hydrogen Evolution Performance of COF-Mediated Systems}

When analyzing the photocatalytic hydrogen production mediated by COFs, several aspects need to be considered to improve the overall yield of the process, which will be listed and further developed in the following subsections.

Photocatalysis starts with the absorption of light by a semiconducting COF and the concomitant formation of electron-hole pairs, also called excitons, that later are dissociated to form charge carriers. Light energy should be higher than the bandgap between the HOMO and LUMO orbitals to excite electrons and lead to the occupation of the CB and the generation of holes (positive charges) in the VB. Thus, to maximize the visible light absorption of the COFs, their bandgaps should be small. This bandgap can be tuned by properly modifying the aromatic nodes and linkages, as will be exemplified later (Section 2.3.2).

After exciton formation upon light absorption, the electron-hole pairs need to be separated into free charges and migrate to the surface of the COF to interact with the 
substrate and perform catalysis. In the HER case, we are interested in the capability of electrons to reduce protons into hydrogen; therefore, the $\mathrm{CB}$ should have a more negative potential than that of the $\mathrm{H}^{+} / \mathrm{H}_{2}$ couple at the working $\mathrm{pH}$. Additionally, holes in the VB need to be consumed by trapping electrons (promoting an oxidation reaction) to compensate for the global charge of the semiconductor. Therefore, when the HER is studied independently from the anodic counterpart (where typically the challenging water oxidation reaction takes place), a sacrificial electron donor (SED) is needed. Thus, SED compounds such as triethanolamine (TEOA), triethylamine (TEA), diethylamine (DEA), and ascorbic acid (AA) as hole scavengers are used to consume the photogenerated holes and facilitate the global photocatalytic process. Usually, the reaction with the SED takes place before the catalytic process itself, and in consequence the former process is responsible for generating long-lived charges. In addition, this process also avoids the degradation of the photocatalyst that the accumulation of energetic holes may cause. However, before such redox processes take place at the surface of the $\mathrm{COF}$, there is the possibility that the photogenerated electrons and holes recombine in the so-called charge recombination process, releasing the initial harvested energy in the form of radiation (fluorescence) or heat, thus decreasing the global performance of the whole photocatalytic process. A general overview of the photocatalytic HER mediated by COFs in a colloidal dispersion is shown in Figure 1a. Another approach that can be used to avoid the use of a SED is the deposition of the COF onto an electrode to be used as working electrode into a photoelectrochemical system. In this approach, the holes generated in the VB will be filled with electrons extracted from the oxidative reaction taking place in the counter electrode (Figure 1b).

(a)

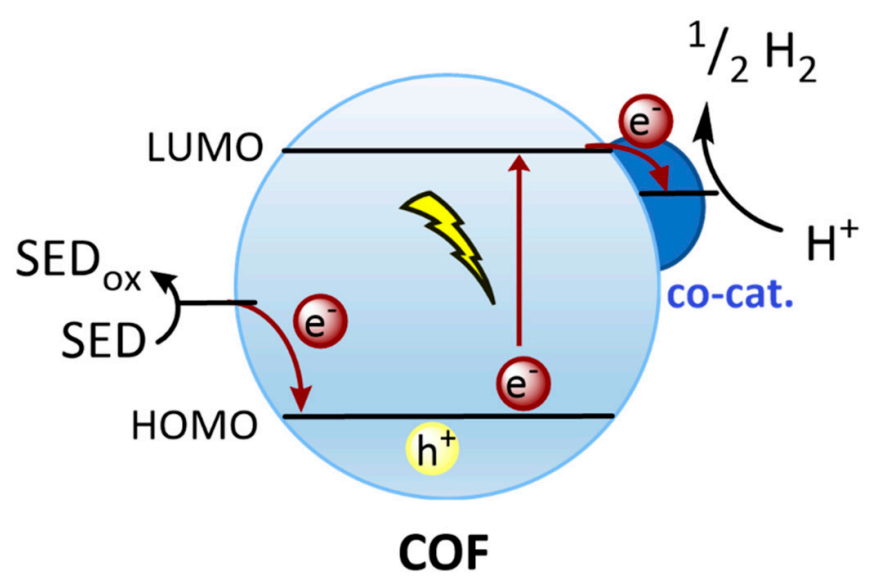

(b)

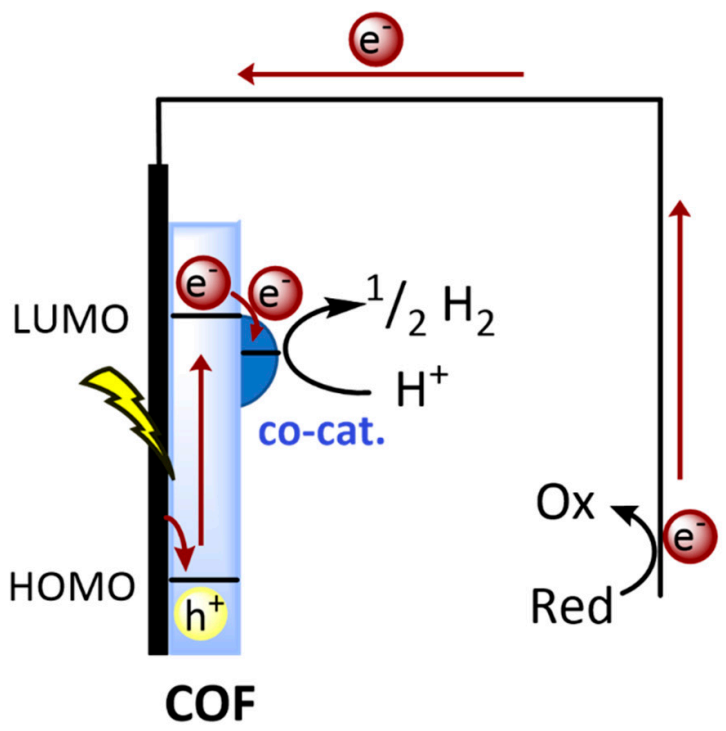

Figure 1. General overview of the photocatalytic HER mediated by COFs in a colloidal dispersion (a) and deposited onto an electrode (b).

Despite the thermodynamic and kinetic aspects related to the photocatalytic process itself described above, the stability and fate of the whole system under turnover conditions cannot be disregarded. This includes both the organic part (COF) and the metallic (co-catalyst) part. Regarding the former, during the last 6 years it has been made clear that imine-derived [18], triazine-containing [9,19-22], diacetylene-containing [23], $\beta$ ketoenamine-derived [23-25], and fully $\pi$-conjugated $\mathrm{sp}^{2} \mathrm{C}$ [26-28] COFs are very resistant under photocatalytic conditions, in contrast to the great tendency towards hydrolysis of boroxine and boronic ester-derived COFs [2,29]. Additionally, N-rich COFs have arisen as highly crystalline, porous, and chemically stable materials, showing enhanced lightharvesting and charge separation properties $[14,29,30]$. Therefore, these systems will constitute the core of this review. In contrast, the fate of co-catalysts under turnover conditions has not been paid much attention yet [9]. 


\subsection{Common Synthetic Pathways to Build Efficient and Robust COFs}

In this section, we will give a short overview of the synthetic pathways (Figure 2) and the building units (Figure 3) that give rise to COFs with remarkable HER photocatalytic properties. Condensation reactions are amongst the most used. For example, Lotsch and collaborators synthesized a series of four azine-linked triphenylaryl COFs by condensation of aldehyde groups with hydrazine (see Figure 2a as a simple condensation example between an arylaldehyde and hydrazine to form an azine linker [14]) containing a central aryl ring with different $\mathrm{N}$ contents, from 0 to $3\left(\mathrm{~N}_{\mathrm{x}}-\mathrm{COF}, \mathrm{x}=0-3\right.$, Figure 4a) [19], which will be thoroughly described in Section 2.2. Another example can be found in the condensation reaction between 2,4,6-trihydroxybenzene-1,3,5-tricarbaldehyde (also named 1,3,5-triformylphloroglucinol, TP) and 3,9-diamino-benzo[1,2-b:4,5- $\left.b^{\prime}\right]$ bis[1]benzothiophene sulfone (Figure $2 b$ ), involving the formation of a Schiff base between the aldehyde and the amino groups after dehydration, and the subsequent irreversible enol-to-keto conversion to form the $\beta$-ketoenamine-linked FS-COF [24] (Figure 4d) containing the sulfone functional groups (FS stands for fused sulfone). Additionally, covalent triazine framework (CTF)-based COFs are among the most relevant photocatalytic examples, whose properties will be discussed later [31]. CTF-COFs can be synthesized under mild conditions by condensation at $120^{\circ} \mathrm{C}$ of aldehydes (e.g., 1,4-benzenedialdehyde, Figure 2c) and amidines (e.g., terephthalimidamide, Figure 2c) involving the formation of a Schiff base between the aldehyde and the amidine groups after dehydration, followed by a Michael addition reaction to form the triazine ring after the elimination of ammonia (Figure 2c) $[20,21]$.

(a) Condensation of arylaldehyde and hydrazine<smiles>NNC(=O)c1ccc(P(O)c2ccc(CN=Cc3ccc(Br)cc3)cc2)cc1</smiles>

(b) Condensation of 1,3,5-triformylphloroglucinol (TP) and 3,9-diamino-benzo[1,2-b:4,5-b']bis[1]benzothiophene sulfone<smiles></smiles>

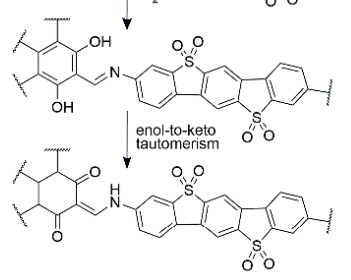

(c) Condensation of 1,4-benzenedialdehyde and terephthalimidamide

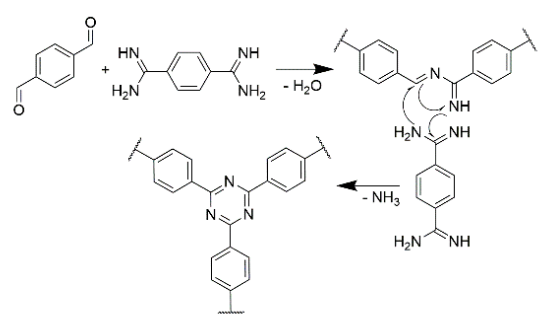

(d) Condensation of 1,3,6,8-tetrakis ( $p$-formylphenyl)pyrene (TFPPyr) and 1,4-phenylenediacetonitrile (PDAN) in the presence of 3-ethylrhodanine (ERDN)

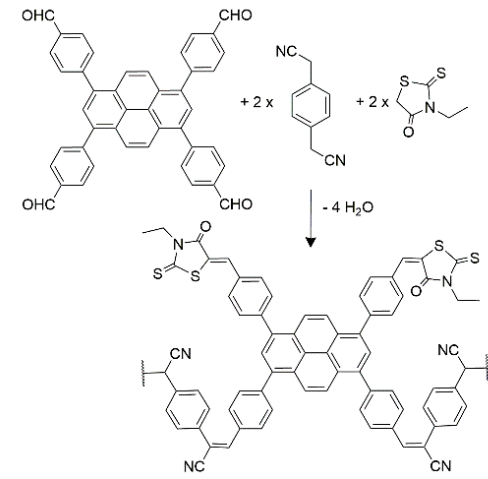

(e) Condensation of 4,4"-diformyl-p-terphenyl (DFPTP) and 3,5-dicyano-2,4,6-trimethylpyridine (DCTMP)

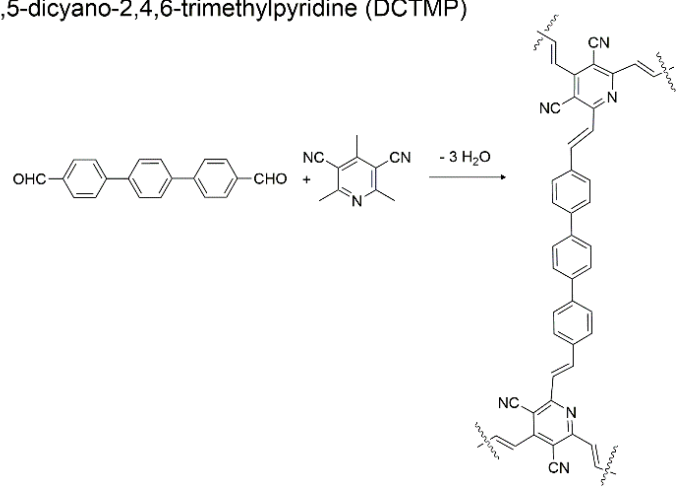

Figure 2. Selected condensation reactions to achieve the synthesis of COFs. Note that for the sake of simplicity only the reactivity of one end of both reactants is shown. 


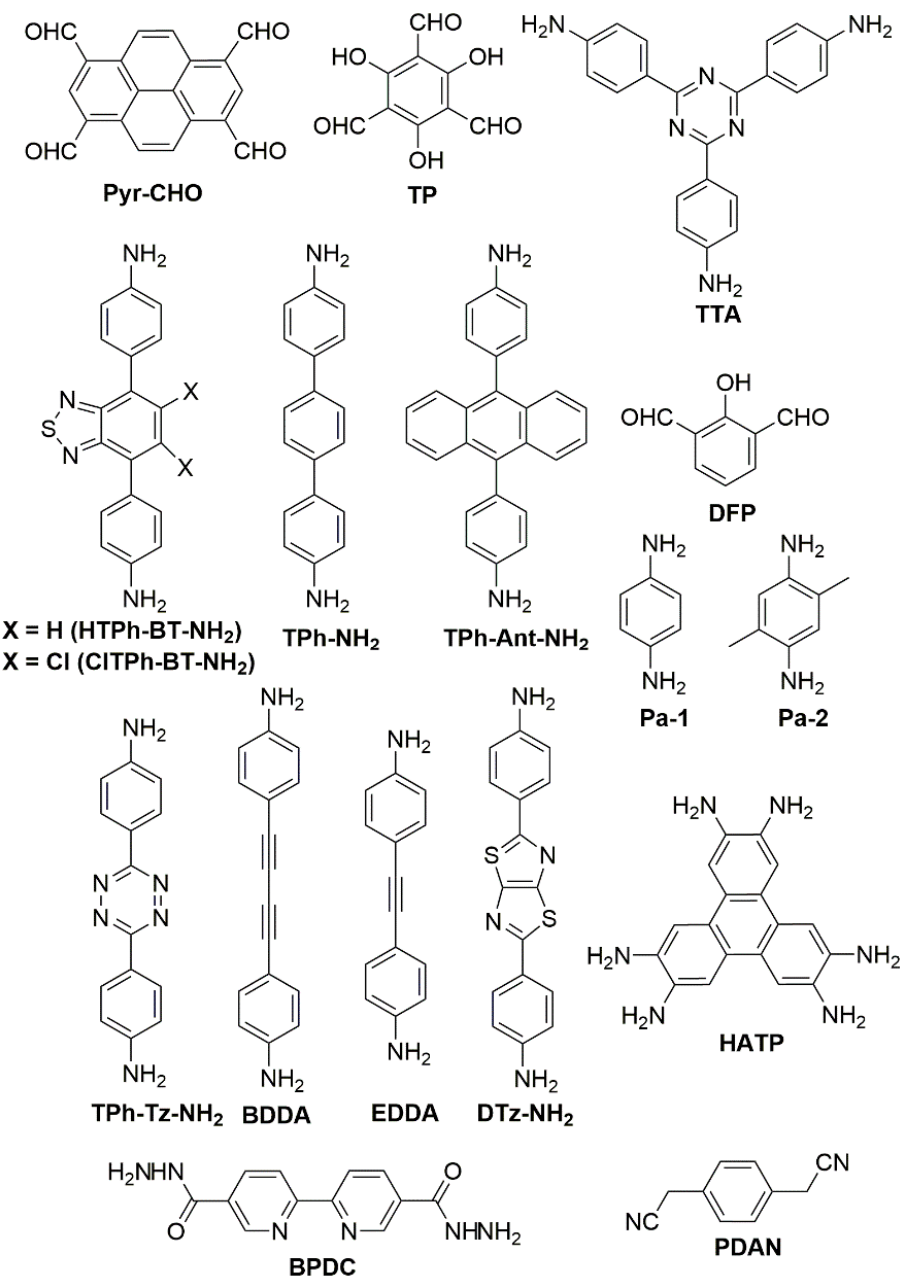

Figure 3. Structures of the starting building blocks used in some of the works cited in this review.

There has been a growing interest in the use of donor-acceptor (D-A) building units in COFs, for example incorporating conjugated aromatic rings (D) and cyano groups (A). In those cases, a pathway to obtain rough $\mathrm{COFs}$ is by $\mathrm{C}=\mathrm{C}$ bond formation. Vinyl bonds are obtained, for example, by condensation between a pyrene D group (1,3,6,8-tetrakis( $p$ formylphenyl)pyrene, TFPPyr) and 1,4-phenylenediacetonitrile (PDAN) in the presence of the A end-capping agent 3-ethylrhodanine (ERDN) for the formation of $\mathrm{sp}^{2} \mathrm{c}-\mathrm{COF}_{\mathrm{ERDN}}$ [26], where TFPPyr has been functionalized with ERDN at the 3,6 positions and linked at the 1,8 positions through $\mathrm{sp}^{2} \mathrm{C}$-bonds to PDAN (Figure 2d). Another remarkable example is shown in Figure 2e, where the $C=C$ bond condensation reaction between 4,4 "-diformyl-pterphenyl (DFPTP) and the methyl groups in 3,5-dicyano-2,4,6-trimethylpyridine (DCTMP) yielded the highly crystalline g- $\mathrm{C}_{40} \mathrm{~N}_{3}$-COF [28] (Figure 4c). In this work, the authors highlight the common difficulties in obtaining highly crystalline COFs containing $\mathrm{C}=\mathrm{C}$ bridges due to the poor reversibility of the traditional $\mathrm{C}=\mathrm{C}$ forming reactions, and the novel synthetic strategy they develop leading to high crystallinity based on a self-healing reversible process. Other D-A building blocks that yield COFs with remarkable activity are also shown in Figure 3. Thus, pyrene (Pyr)-containing D-A COFs have been synthesized by fusion of the $\mathrm{D}$ unit $4,4^{\prime}, 4^{\prime \prime}, 4^{\prime \prime \prime}$ (pyrene-1,3,6,8-tetrayl)benzaldehyde (Pyr-CHO) with a terphenyl (TPh)-based diamine annulated with the A unit benzothiadiazole (BT) - both unmodified, HTPh-BT-NH $\mathrm{N}_{2}$, and dichlorinated, ClTPh-BT- $\mathrm{NH}_{2}$ - after condensation of the terminal aldehyde and amino groups through formation of imine bonds [18]. 
(a)

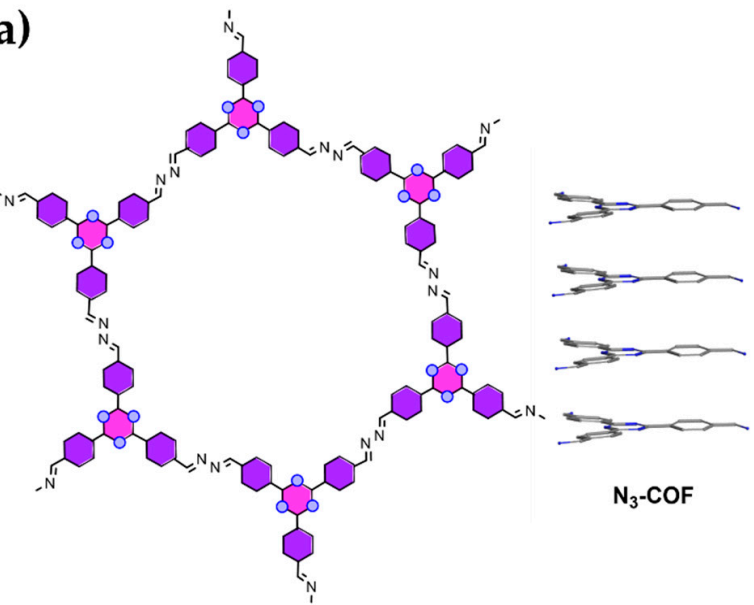

$\mathrm{N}_{\mathrm{x}} \mathrm{COF} \circlearrowleft=$

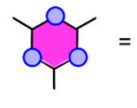<smiles>Cc1cc(C)cc(C)c1</smiles><smiles>Cc1cc(C)nc(C)c1</smiles><smiles>Cc1cc(Cc2nc(C)nc(C)n2)nc(C)n1</smiles>
PTP-COF<smiles>Cc1ccc(I)cc1</smiles>

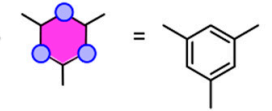

(c)

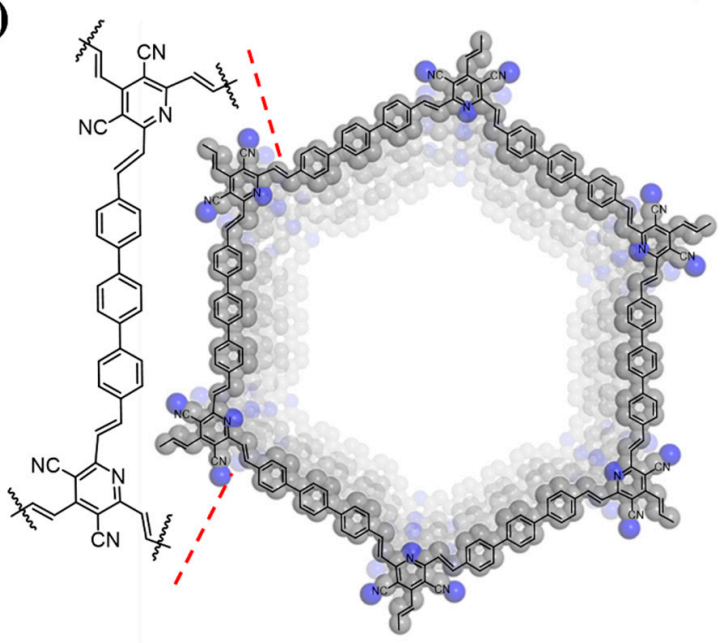

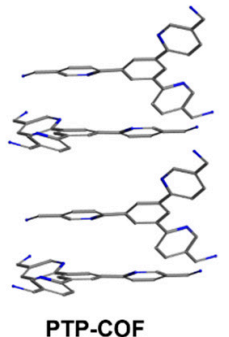

(b)

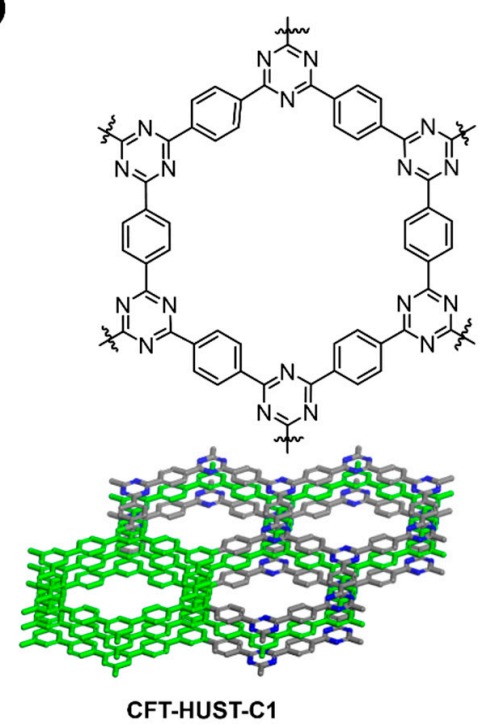

CFT-HUST-C1

(d)
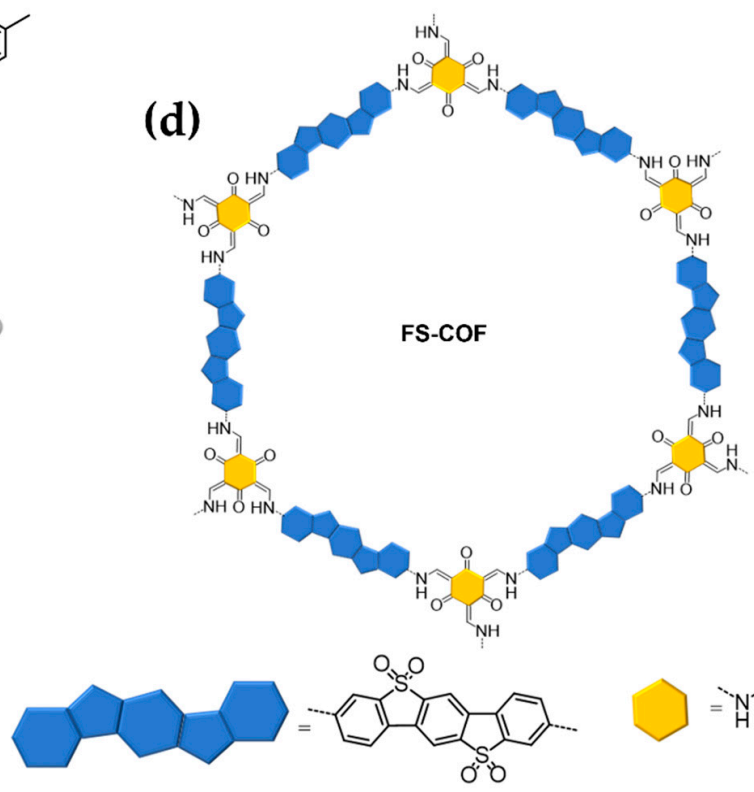

Figure 4. Highly crystalline $\mathrm{N}_{\mathrm{x}}-\mathrm{COFs}(\mathrm{x}=0-3)$ and the PTP-COF [19] (a), CTF-HUST-C1 [20] (b), the g-C ${ }_{40} \mathrm{~N}_{3}-\mathrm{COF}$ [28] (c), and the FS-COF [24] (d). The $\pi$-stacking interactions in the $\mathrm{N}_{3}-\mathrm{COF}$ and PTP-COF are also displayed in (a).

Tuning the building blocks has also been explored for some COFs, leading to rationally improved activities. For example, Zhang et al. obtained COFs of different pore sizes and crystallinities via the condensation reaction of arylmethyl $\mathrm{C}$ atoms with aromatic aldehydes derived from terphenyl, biphenyl, or trisphenylbenzene [28]. Due to its appropriate band energy levels, the system with a terphenyl spacer and larger pores, g- $\mathrm{C}_{40} \mathrm{~N}_{3}$-COF (Figure 2e, Figure 4c), resulted the most active in the HER. Additionally, $\beta$-ketoenamine linked honeycomb-like COFs have been formed by condensation of 1,3,5triformylphloroglucinol (TP) with 4,4'-diamino- $p$-terphenyl $\left(\mathrm{TPh}-\mathrm{NH}_{2}\right)$ and three derivatives consisting in replacing the central phenyl ring by anthracene (Ant), tetrazine (Tz), or benzothiadiazole (BT), namely TPh-Ant- $\mathrm{NH}_{2}, \mathrm{TPh}-\mathrm{Tz}-\mathrm{NH}_{2}$, and $\mathrm{HTPh}-\mathrm{BT}-\mathrm{NH}_{2}$, as depicted in Figure 3, in order to study the effect of the linker in isoreticular COFs in the overall HER photocatalytic activity [32]. Another crystalline $\beta$-ketoenamine linked COF (TP-BDDA $\mathrm{COF}$ ) has been synthesized by Thomas et al., in this case bearing diphenyl diacetylene bridges, by mixing TP and 4,4'-(buta-1,3-diyne-1,4-diyl)dianiline (BDDA) (Figure 3) [23]. The importance of the presence of the diacetylene bridges is made clear when comparing 
the behavior of the TP-BDDA COF (showing steady photochemical $\mathrm{H}_{2}$ evolution for $10 \mathrm{~h}$ ) with that of the corresponding COF with a diphenyl acetylene bridge instead (TP-EDDA COF, EDDA standing for 4,4'-(ethyne-1,2-diyl)dianiline), Figure 3. For the latter, almost no hydrogen evolution is observed.

Other functionalization steps have been explored to favor the coordination of metals other than $\mathrm{Pt}$ as co-catalysts. Thus, the imine-linked HDCOF formed by reaction of 2,3,6,7,10,11-hexaaminotriphenylene (HATP) with 2,6-diformylphenol (DFP) offers $\mathrm{N}, \mathrm{N}, \mathrm{O}, \mathrm{O}-$ tetradentate Shiff base sites to coordinate $\mathrm{Cu}(\mathrm{II})$ ions [33]. Additionally, a Co-modified hydrazone-based NUS-55 COF has been synthesized by reaction of 2,2'bipyridine-5,5'-dicarbohydrazine (BPDC) and 1,3,5-triformylphloroglucinol (TP) [34]. All these building units are plotted in Figure 3.

Finally, a recent report has demonstrated the great power of the post-functionalization strategies. In this work, a $\beta$-ketoenamine linked COF derived from TP and bipyridine (TP-Bpy-COF) was covalently modified by reaction with 1,2-dibromoethane, yielding the quaternization of some of the Bpy-bridging units. The ethylene bridge formed between two cationic adjacent $\mathrm{N}$ atoms $\left(\mathrm{Tp}-2 \mathrm{C} / \mathrm{Bpy}^{2+}-\mathrm{COF}\right)$ acts as an integrated electron mediator, resulting in a concomitant increase in photocatalytic HER activity when combined with a $\mathrm{Pt}$ co-catalyst [35]. Another post-functionalization strategy has also been reported recently, in which a CTF-COF has been treated in $\mathrm{HCl}$ after having been exfoliated by ball-milling, thus generating the formation of $\mathrm{Cl}$-intercalated CTF- 1 through $\mathrm{Cl}-\mathrm{C}$ and $\mathrm{Cl}-\mathrm{N}$ covalent bonds within the triazine ring [36]. The formed COF interlayer channels facilitate charge separation and mobility as well as a narrowing of the bandgap, therefore enhancing its light absorption and photocatalytic HER capabilities.

\subsection{Secondary Interactions}

In addition to the covalent bonds, secondary interactions, mostly $\pi$-stacking of aromatic rings, play a relevant role in the photocatalytic activity of COFs, as they govern their porosity and increase their crystallinity to a great extent. A high degree of crystallinity provides efficient pathways for charge separation and transport as well as a broader light absorption capability and higher thermal/photocatalytic stability.

A paradigmatic example is found for $\mathrm{N}_{\mathrm{x}}-\mathrm{COFs}(\mathrm{x}=0-3$, Figure $4 \mathrm{a})$, where the crystallinity is strongly dependent on the geometrical constraints imposed by the central aromatic nodes. Thus, with increased $\mathrm{N}$ content the dihedral angle between the central ring and the surrounding rings decreases, increasing the planarity of the layers. This favors the crystallinity and porosity of the systems and facilitates the charge mobility through the layers and in the axial direction as well, which yields faster $\mathrm{H}_{2}$ production and higher $\mathrm{AQE}$ values [19]. In addition, the increase in crystallinity leads to an increase in the number of $\mathrm{N}_{\mathrm{X}^{-}}$ COF layers, which in turn provokes an increase in the HOMO energy level and a decrease in the LUMO one, leading to a decreased bandgap and a higher visible light absorption capability [19]. Furthermore, the replacement of the central triazine ring of $\mathrm{N}_{3}-\mathrm{COF}$ by a phenyl ring and of the terminal 4-benzaldehyde groups by 3-pyridinecarboxyaldehyde yields a phenyl-tripyridyl-derived COF (PTP-COF, Figure 4a) [37], allowing for the analysis of the differences between the two COFs containing the three $\mathrm{N}$ atoms at different positions. The lower symmetry of the PTP-COF compared with the $\mathrm{N}_{3}$-COF leads to higher disorder for the former and thus lower crystallinity and porosity, since there is a higher number of possible molecular conformations around the torsion angle between the central phenyl ring and the peripheral pyridine rings than between the central triazine ring and the external phenyl substituents. In contrast to the face-to-face $\pi$-stacking interactions observed in the $\mathrm{N}_{3}$-COF, PTP-COF crystals (Figure 4a) are less ordered due to the interactions between the donor phenyl groups and the acceptor pyridine rings. Furthermore, the higher basicity of pyridine compared with triazine leads to H-bonding interactions between the pyridyl groups in PTP-COF crystals, leading to oligomers or molecules occluding the pores. In short, the different constitutive aromatic rings in the PTP-COF compared with the $\mathrm{N}_{3}$-COF 
directly point to a lower crystallinity and porosity of the former, which shows a poorer dispersibility in water as well, with the consequent diminished light absorption capacity.

There are more examples in the literature demonstrating that the photocatalytic HER is improved with an increased crystallinity of the COF scaffold. This is the case for the two following works of Tan et al. dealing with CTF-COFs [20,22]. In the first example [20], the substitution of an aldehyde precursor by its corresponding alcohol analogue led to a decrease in the reaction rate of formation of the triazine-based COFs. The subsequent decrease in the nucleation rate results in a significant increase in the crystallinity degree of the final CTF-COFs obtained and thus of their photocatalytic HER activity with respect to CTF-COF analogues of low crystallinity. For example, when combined with Pt as co-catalyst, the crystalline CTF-HUST-C1 (Figure 4b) displayed a 4.75-fold increase in the $\mathrm{H}_{2}$ evolution rate than its corresponding low-crystalline analogue, CTF-HUST-1. In the second example [22], the same CTF-COF was synthesized starting from the 1,4-phenylenedimethanamine precursor instead of the previous aldehyde or alcohol precursors, which in the presence of a strong base ( $\left.{ }^{\mathrm{t}} \mathrm{BuOK}\right)$ produced in a high yield $(99.2 \%)$ the highly crystalline and hydrophilic (wettable) CTF-HUST-A1 COF. By using $\mathrm{Pt}$ as co-catalyst and TEOA as SED, this system displayed a 6.3-fold increase in the hydrogen evolution rate compared with CTF-HUST- 1 , that is, $9.2 \mathrm{mmol} \mathrm{H}_{2} \cdot \mathrm{g}^{-1} \cdot \mathrm{h}^{-1}$, and a high AQE of $7.4 \%$ at $420 \mathrm{~nm}$. Furthermore, in this work the authors also demonstrate a gradual increase in the crystallinity of the obtained CTF-HUST-A1 with the strength of the base used for its synthesis, which also correlates with a large increase in the lifetime of the photogenerated charges according to transient absorption spectroscopy. Similarly, the crystalline FS-COF (Figure 4d) shows a 9-fold higher $\mathrm{H}_{2}$ production than its amorphous counterpart using Pt as co-catalyst and AA as SED [24], and the crystalline $\mathrm{sp}^{2} \mathrm{c}-\mathrm{COF}$ shows a one order of magnitude higher photocatalytic activity than its amorphous counterpart using Pt as co-catalyst and TEOA as SED [26]. Another family of highly crystalline COFs are the $\mathrm{sp}^{2} \mathrm{C}$-linked ones containing trans-disubstituted $\mathrm{C}=\mathrm{C}$ bonds, among which the g- $\mathrm{C}_{40} \mathrm{~N}_{3}$-COF (Figure 2e, Figure 4c) is the most active in the photocatalytic HER [28].

COFs' crystallinity is closely related to the stability of the systems in the photocatalytic HER. Thus, monitoring its evolution with time under turnover conditions becomes key to understanding the durability and fate of the tested systems. Thus, for example, the highly crystalline imine-linked Pyr-ClTPh-BT-COF [18] and the triazine-linked $\mathrm{N}_{3}-\mathrm{COF}$ [19], possessing planar $\pi$-delocalized planes and $\pi-\pi$ stacking interactions between parallel planes, produce $\mathrm{H}_{2}$ under continuous irradiation at $\mathrm{pH} 7$ for 2 days without any crystallinity or porosity loss. Other examples of crystalline COFs with long-term stability under photocatalytic HER conditions are the $\beta$-ketoenamine-linked FS-COF [24] and the TpDTz-COF [25]. These COFs (see Section 2.5), and a recently reported thiazole (TZ)-bridged highly porous fully aromatic framework [38], all exhibit photocatalytic hydrogen evolution for more than $50 \mathrm{~h}$ with no sign of crystallinity degradation.

There is only one exception to the rule that directly relates crystallinity and photochemical HER activity [32]. In this work, Seki, Abe et al. systematically analyze the effect of all possible factors on the photocatalytic $\mathrm{H}_{2}$ evolution activity of the $\beta$-ketoenamine linked honeycomb-like COFs TPh-Ant- $\mathrm{NH}_{2}, \mathrm{TPh}-\mathrm{Tz}-\mathrm{NH}_{2}$, and HTPh-BT- $\mathrm{NH}_{2}$ (Figure 3). The authors conclude that neither their degree of crystallinity nor the torsional angle between the external aniline rings and the central aromatic ring in TPh and derivatives are crucial for catalysis. Instead, charge mobility is facilitated by the eclipsed $\mathrm{AA}^{\prime}$ stacking between adjacent parallel planes compared with $\mathrm{AB}$ or $\mathrm{ABC}$ stackings, which can be obtained under different reaction conditions (solvent and temperature).

Finally, in addition to the $\pi$-stacking interactions between the aromatic rings, the secondary interactions between the COFs and the solvent, water in this case, are also key to achieving high photocatalytic activities. This is the case for the FS-COF [24], where the presence of sulfone polar groups increases its effectively exposed internal surface area in front of water, thus increasing its wettability and photocatalytic activity. In consequence, under identical photocatalytic conditions, the FS-COF shows a 22-fold higher $\mathrm{H}_{2}$ produc- 
tion and a superior $\mathrm{AQE}$ than the $\mathrm{N}_{3}-\mathrm{COF}$, which lacks the sulfone groups and shows reduced wettability in the reaction media.

\subsection{Electronic Effects}

To increase the HER photocatalytic performance of COFs, one must improve: (1) their charge separation and transfer abilities; (2) their charge generation capacity (improving light absorption by bandgap tuning); and (3) the stabilization of the key intermediates formed. All these can be achieved by tuning the electronic properties of the prepared COFs. In the following subsections, we will discuss which successful strategies have been used to this aim.

\subsubsection{Charge Separation and Transfer}

A successful way to promote charge separation and transfer consists in constructing electron donor-acceptor (D-A) interfaces that favor the formation of weak charge transfer excitons with low binding energy that easily dissociate. This leads to spatially separated charges with slower recombination kinetics. Thus, more charges can be used in catalysis (usually taking place at longer time scales). D-A arrays are especially relevant in ordered $\pi$-stacked 2D-COFs, where both in-plane and out-of-plane $\pi$ charge delocalizations among the parallel planes take place. They allow for rapid charge separation and a long lifetime for spatially separated electrons and holes, which follow opposite directions across the periodic columns, therefore avoiding charge recombination (Figure 5). This clearly represents an advantage compared with 3D-COFs, where these interplanar interactions cannot exist [39]. One relevant example can be found in the fully $\pi$-conjugated $2 \mathrm{D} \mathrm{sp}{ }^{2} \mathrm{c}-\mathrm{COF}_{\mathrm{ERDN}}$ [26] (Figure 2d, Figure 5). In this example, the effect of the electron acceptor ERDN end-capping molecules is key, since they further enhance $\pi$-conjugation through electronic D-A pushpull effects. In addition, the D-A COF structure leads to a more efficient electron generation thanks to the facilitated exciton splitting into free charges.
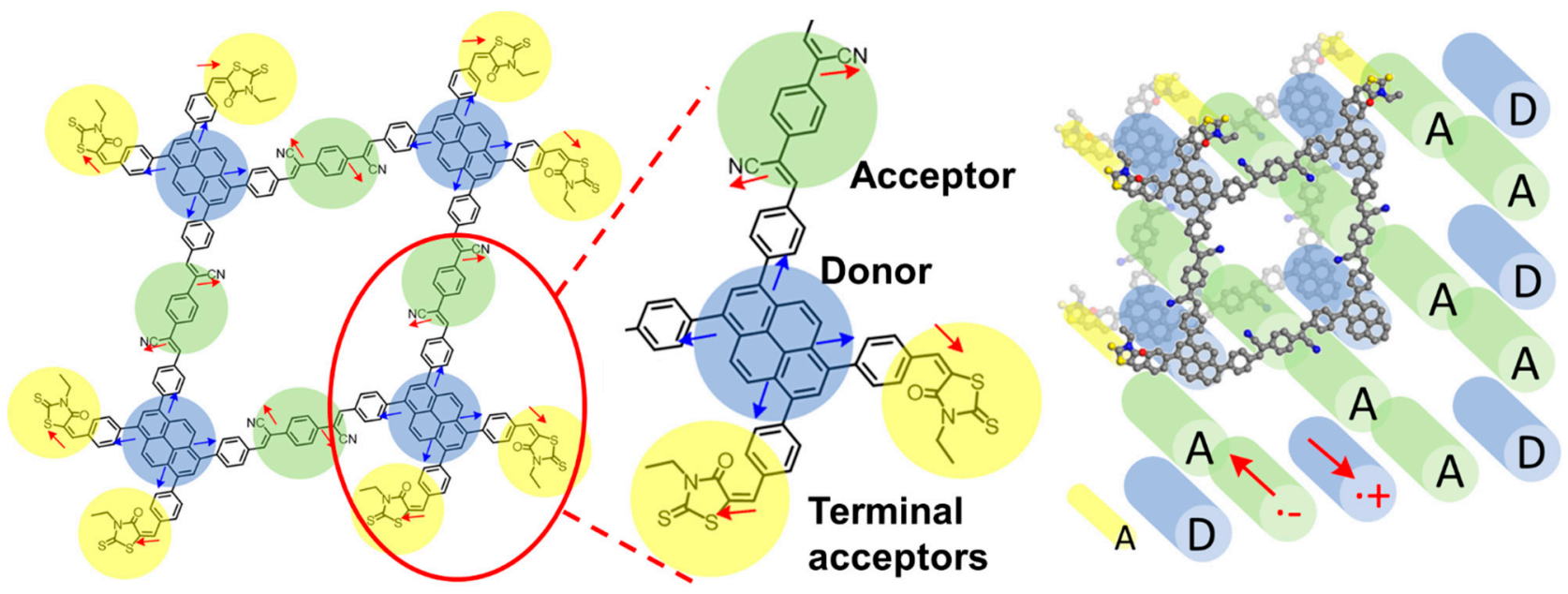

Figure 5. Structure of $\mathrm{sp}^{2} \mathrm{c}-\mathrm{COF}_{\mathrm{ERDN}}$ [26] containing D-A units and paths for electrons and holes through the $\pi$-stacking interactions.

A second example of a very active COF containing D-A units (AQE of $6.7 \%$ at $420 \mathrm{~nm}$ in the presence of $3 \mathrm{wt} \% \mathrm{Pt}$ ) has been described for another alkene-linked framework, in which triphenylbenzene nodes (D units) are linked through trans $\mathrm{CN}$-substituted $p$-dialkene benzene bridges (A units) [40]. The efficient charge separation and transfer properties of this system are due to the strong electron withdrawing ability of the $\mathrm{CN}$ groups and the good electron delocalization of the whole framework, which slow down undesired recombination processes. Likewise, a recently described crystalline bithiophene-bridged 2D sp ${ }^{2}$ C-linked conjugated COF (2D CCP-Th), containing both D (thiophene) and A 
(cyano) groups, shows an intense $\mathrm{H}_{2}$-evolution photocurrent density $\left(7.9 \mu \mathrm{A} \cdot \mathrm{cm}^{-2}\right.$ at $0 \mathrm{~V}$ vs. RHE), superior to that of other reported 2D-COFs [27]. Additionally, the positive effect of the presence of D-A units can be found as well for the $\beta$-ketoenamine linked TPh-Ant$\mathrm{NH}_{2}$, TPh-Tz-NH $\mathrm{N}_{2}$, and HTPh-BT-NH $\mathrm{N}_{2} \mathrm{COFs}$ (Figure 3). The photocatalytic activity of the best system, HTPh-BT- $\mathrm{NH}_{2}$, has been assigned to the A ability of the benzothiadiazole (BT) bridging unit [32]. Finally, an alternative way to create D-A pathways is the use of hydrazone-linked 2D porphyrinic COFs containing different metal ions (Co(II), $\mathrm{Ni}(\mathrm{II})$, $\mathrm{Zn}(\mathrm{II}))$ within the porphyrin binding site [41]. Among the different assayed metals, the $\mathrm{d}^{10} \mathrm{Zn}$ (II) system is reported to be the most active, efficiently avoiding electron-hole recombination processes. Holes travel throughout the parallel aromatic hydrazone linkers while electrons freely migrate all the way through the parallel $\mathrm{Zn}(\mathrm{II})$-porphyrinic rings.

\subsubsection{Charge Generation}

Together with aiding charge separation (see the previous subsection), electronic effects can also reduce the COFs' bandgap and increase their capability of absorbing light in the visible region. By absorbing more visible photons under sunlight irradiation, the systems will be able to yield more free charges to be used in the HER. In the literature, this has been achieved via several strategies: (1) by introducing D-A units, as explained in the previous subsection; (2) by an extended conjugation of the structure of COFs; and (3) by controlled exfoliation.

Several COFs bearing D-A units have shown the capacity to increase charge generation under visible light irradiation by narrowing their bandgap. For instance, the fully $\pi$ conjugated 2D sp ${ }^{2} \mathrm{c}-\mathrm{COF}_{\mathrm{ERDN}}$ [26] (Figure 2d, Figure 5), apart from a more efficient charge separation, also presents a reduced bandgap from $1.90 \mathrm{eV}$ (for sp ${ }^{2} \mathrm{c}-\mathrm{COF}$, in the absence of ERDN) to $1.85 \mathrm{eV}$, therefore red-shifting by $33 \mathrm{~nm}$ its near-infrared light absorption capacity up to $800 \mathrm{~nm}$.

Extended conjugation is a second relevant factor influencing charge generation. An example of this effect can be found in the terphenyl (TPh) bridged g- $\mathrm{C}_{40} \mathrm{~N}_{3}-\mathrm{COF}$, where conjugation induces a decrease in the bandgap $(2.36 \mathrm{eV})$ and an increase in the average fluorescence lifetime (3.31 ns) compared with the analogous COFs with shorter biphenyl ( $2.40 \mathrm{eV}, 2.71 \mathrm{~ns})$ or phenyl ( $2.52 \mathrm{eV}, 2.58 \mathrm{~ns})$ spacers [28]. Furthermore, extended conjugation could also explain why the $\mathrm{g}-\mathrm{C}_{40} \mathrm{~N}_{3}-\mathrm{COF}$ is even significantly active in the absence of $\mathrm{Pt}$, where DFT calculations indicate that the $\mathrm{N}$ atom of the pyridine ring is the dominant active site for photocatalytic $\mathrm{H}_{2}$ evolution. However, in the presence of $3 \mathrm{wt} \% \mathrm{Pt}$ as cocatalyst its activity increases, reaching an AQE at $420 \mathrm{~nm}$ as high as $4.84 \%$ [28], exceeding that of the triazine-derived $\mathrm{N}_{3}-\mathrm{COF}$ [19], the hydrazone-based TFPT-COF [9], and the sulfone-containing FS-COF [24].

Finally, another way to narrow the bandgap of COFs is by controlled exfoliation. This has been reported for the case of a CTF-COF in which the exfoliated nanosheets show improved visible light absorption properties and shortened diffusion lengths of the photoexcited electrons compared with the bulk CTF-COF [42]. Analogously, besides its considerable wettability, the extraordinary HER photocatalytic activity of the FS-COF has also been attributed to its partial exfoliation capacity [24].

\subsubsection{Stabilization of Key Intermediates}

The modulation of the HOMO and LUMO orbital energies upon COF modification can also stabilize or destabilize intermediates, affecting the probability of recombination reaction processes. For example, for $\mathrm{N}_{\mathrm{x}}-\mathrm{COFs}$, the HOMO and LUMO energy levels decrease when increasing the $\mathrm{N}$ content of the central aryl ring [19]. A lowered HOMO energy level increases the oxidation ability of holes in $\mathrm{N}_{\mathrm{x}}$-COFs, thus enhancing hole removal by the sacrificial electron donor (TEOA), which correlates with an increased HER photocatalytic activity with increasing $\mathrm{N}$ content (a 74-fold increase in $\mathrm{H}_{2}$ production and a 4400-fold increase in AQE is observed from $x=0$, central phenyl ring, to $x=3$, central triazine ring, Figure 4a). Furthermore, the authors propose that the formation of a radical 
anion might be the rate-determining step of the overall process, and this radical anion is stabilized with an increasing $\mathrm{N}$ content of the central aryl ring, as $\mathrm{N}$ acts as an electronwithdrawing group. Thus, the increased stability of the radical anion with increasing $\mathrm{N}$ content is in line with the observed trend of increased HER photocatalytic activity as the $\mathrm{N}$ content increases. Additionally, an increased stability of the radical anion suggests a more effective charge separation process, thus facilitating photocatalysis [19]. Contrastingly, the PTP-COF related system (Figure 4a) shows an experimental reduced non-radiative deactivation capacity of the photoexcited states via charge-transfer pathways compared with the more crystalline analogue $\mathrm{N}_{3}-\mathrm{COF}$ [19]. Although the bandgap for PTP-COF is lower than that for $\mathrm{N}_{3}-\mathrm{COF}(2.1 \mathrm{eV}$ vs. $2.7 \mathrm{eV})$, theoretical calculations show that the HOMO and LUMO of the PTP-COF possess a similar spatial extent, thus facilitating the undesired charge recombination processes, and indicate as well that the radical anion in the PTP-COF is significantly less stable than in the $\mathrm{N}_{3}-\mathrm{COF}$ due to the worse capability of pyridine rings to stabilize negative charges than triazine rings.

Finally, an increase in the average lifetime of the photoexcited states and a decrease in the charge transfer barrier due to the electronic effects related to the presence of electron acceptor chlorine atoms has been reported. Thus, for the Pyr-HTPh-BT-COF and the PyrClTPh-BT-COF [18] (Figure 3), although they show similar bandgaps (2.25 and $2.36 \mathrm{eV}$, respectively), the chlorination of the BT ring provokes an 8-fold enhancement of the photocatalytic HER activity due to increased delocalization of electrons and charge density, the latter assisting in a dramatical reduction in the charge transfer barrier. Further, the average lifetime of the photoexcited carriers is enhanced 1.9 times up to $3.88 \mathrm{~ns}$ because of suppression of radiative charge recombination processes, and the AQE increases up to $8.45 \%$ at $420 \mathrm{~nm}$, whereas DFT calculations indicate that the energy barrier for the observed $\mathrm{H}^{*}$ intermediate in some sites is reduced by $0.83 \mathrm{eV}$ compared with the non-chlorinated sample [18].

\subsection{Heterojunctions and Encapsulation of COFs with Other Materials}

A very successful alternative way to facilitate the spatial separation of photogenerated electrons and holes and thus slow down their recombination is to hybridize COFs with either metallic conductors, inorganic semiconductors, or inorganic polymers (MOFs) through the use of heterojunctions. The underlying idea consists in the good matching bandgaps of the COF and the inorganic component of the hybrid systems, favoring charge separation across the two materials. The efficient charge separation across the covalent heterojunction interface in these hybrid materials makes them greatly efficient for this photocatalytic process, yielding superior $\mathrm{H}_{2}$ formation rates. Some significant examples are listed below: (1) the 2D/2D organic/inorganic hybrid composed of a honeycomb-like $\beta$-ketoenamine linked COF deposited in situ on top of an amine-substituted titanium carbide derivative $\left(\mathrm{NH}_{2}-\mathrm{Ti}_{3} \mathrm{C}_{2} \mathrm{~T}_{\mathrm{x}}\right)$ through covalent Ti-O bonds [43], yielding a $\mathrm{H}_{2}$ production as high as $14.2 \mathrm{mmol} \cdot \mathrm{g}^{-1} \cdot \mathrm{h}^{-1}$ in the presence of $\mathrm{Pt}$ and an elevated AQE at $420 \mathrm{~nm}$ of $7.75 \%$; (2) the $\beta$-ketoenamine linked COF obtained from reaction of TP with HTPh-BT-NH 2 (Figure 3) deposited on top of $\mathrm{g}-\mathrm{C}_{3} \mathrm{~N}_{4}$, yielding $11.7 \mathrm{mmol} \mathrm{H} \cdot \mathrm{g}^{-1} \cdot \mathrm{h}^{-1}$ in the absence of $\mathrm{Pt}$ and $26.0 \mathrm{H}_{2} \cdot \mathrm{g}^{-1} \cdot \mathrm{h}^{-1}$ in the presence of $\mathrm{Pt}$ [44]; (3) CTF-HUST-C1 deposited on top of $2 \mathrm{~nm}$-thick black phosphorus nanosheets through P-C covalent bonds, yielding $17.1 \mathrm{mmol}$ $\mathrm{H}_{2} \cdot \mathrm{g}^{-1} \cdot \mathrm{h}^{-1}$ in the absence of Pt [45]; (4) the MOF@COF system where a 20 nm hydrazonelinked COF shell was grown on top of the octahedral $\mathrm{NH}_{2}-\mathrm{UiO}-66 \mathrm{Zr}$-based MOF through imine bonds, achieving a photocatalytic $\mathrm{H}_{2}$ evolution of $7.2 \mathrm{mmol} \cdot \mathrm{g}^{-1} \cdot \mathrm{h}^{-1}$ in the presence of $\mathrm{Pt} \mathrm{[46];} \mathrm{(5)} \mathrm{the} \mathrm{inverse} \mathrm{approach} \mathrm{in} \mathrm{which} \mathrm{a} \mathrm{NH}_{2}-\mathrm{UiO}-66 \mathrm{Zr}$-based MOF layer was deposited through imine covalent bond formation on top of a honeycomb-like $\beta$-ketoenamine linked COF (TpPa-1-COF) generated from reaction of TP with $p$-phenylenediamine (Pa-1) (Figure 3) to generate an extremely active COF@MOF hybrid system that yields $23.4 \mathrm{mmol}$ $\mathrm{H}_{2} \cdot \mathrm{g}^{-1} \cdot \mathrm{h}^{-1}$ also in the presence of Pt [47]; and (6) the doping of a biphenyl-bridged CTF-based COF (CTF-HC2) with a 2D-Ni(II) pyrimidine-2-thiolate framework [48]. 
Other strategies used have consisted in (1) the encapsulation of $\left[\mathrm{Mo}_{3} \mathrm{~S}_{13}\right]^{2-}$ anionic clusters into the channels of the positively charged honeycomb-like $\beta$-ketoenamine linked COF generated from reaction of TP (Figure 3 ) with ethidium bromide, generating a remarkable HER photocatalyst able to produce $13.2 \mathrm{mmol} \mathrm{H} \cdot \mathrm{g}^{-1} \cdot \mathrm{h}^{-1}$ over $18 \mathrm{~h}$ in the absence of $\mathrm{Pt}$ [49]; (2) the covalent modification of graphitic carbon nitride nanosheets (GCNS) by imine covalent bonding to the imine-linked COF formed from $4,4^{\prime}, 4^{\prime \prime}-(1,3,5$ triazine-2,4,6-triyl)trianiline (TTA) and TP (Figure 3), yielding the extraordinary value of $46.4 \mathrm{mmol} \mathrm{H} \cdot \mathrm{g}^{-1} \cdot \mathrm{h}^{-1}$ and an AQE of $31.8 \%$ at $425 \mathrm{~nm}$ in the presence of $\mathrm{Pt}$ [50]; and (3) the covalent anchoring of TpPa-1-COF onto reduced graphene oxide (rGO), achieving $12.0 \mathrm{mmol} \mathrm{H}_{2} \cdot \mathrm{g}^{-1} \cdot \mathrm{h}^{-1}$ in the presence of Pt [51].

In addition, two very interesting systems that do not need a Pt co-catalyst to be significantly active emerge from the combination of hexagonal hematite $\left(\alpha-\mathrm{Fe}_{2} \mathrm{O}_{3}\right)$ nanosheets on top of the honeycomb-like $\beta$-ketoenamine linked TpPa-2-COF generated from reaction of TP with 2,5-dimethyl-p-phenylenediamine (Pa-2) (Figure 3) [52], rendering $3.8 \mathrm{mmol} \mathrm{H}_{2} \cdot \mathrm{g}^{-1} \cdot \mathrm{h}^{-1}$; and from the in situ growth of the TpPa-1-COF in exfoliated $\mathrm{MoS}_{2}$, generating a hybrid system where $\mathrm{MoS}_{2}$ is deposited on top of the TpPa-1-COF [53]. Other possibilities include the deposition of CdS NPs on top COFs, such as the TpPa2-COF [54] or the CTF-1-COF [55]; and the use of $\mathrm{TiO}_{2}$ nanosheets functionalized with 3-aminopropyltriethoxysilane (APTES) to chemically bind TpPa-1-COF onto its surface by imine bond formation [56], yielding $11.2 \mathrm{mmol} \mathrm{H}_{2} \cdot \mathrm{g}^{-1} \cdot \mathrm{h}^{-1}$ and an AQE of $7.6 \%$ at $420 \mathrm{~nm}$ in the presence of Pt.

Finally, a completely different approach to promote efficient charge separation and larger photoexcitation rates as well as decreased non-radiative recombination processes consists in the insulation of the Pt NPs with a PVP-shell, which physically separates the COF from the co-catalyst but does not avoid their mutual electronic communication through electron tunneling. In the case of the TpTa-1-COF, the presence of the PVP-shell surrounding the Pt co-catalyst increases the whole photocatalytic HER efficiency up to 32 times, yielding a $\mathrm{H}_{2}$ production of $8.4 \mathrm{mmol} \mathrm{g}^{-1} \cdot \mathrm{h}^{-1}$ [57].

\subsection{Choice of Metal Co-Catalyst}

As stated before, only a few COFs have shown significant photochemical activity in the HER without the need to add a metal-based co-catalyst [18,27,28,52,53]. Among the different transition metals able to promote the HER, until now very few works have used a metal co-catalyst other than Pt either in the molecular form or as NPs. Apart from enhancing the HER kinetics, co-catalysts can also reduce charge recombination by spatially separating and stabilizing charges. This highlights the need to tune the COF/co-catalyst interface to enhance the charge transfer to the co-catalyst and reduce charge recombination. A clear example is the case of non-covalently bonded molecular co-catalysts. Physically separated from the COF and working through outer-sphere electron-transfer processes, they show the competitive advantage of blocking charge recombination events. Thus, Lotsch et al. incorporated three different cobaloxime(III) co-catalysts within the azine-linked $\mathrm{N}_{2}-$ COF (Figure 4a) [58]. The same research group introduced a Ni thiolate hexameric cluster assembled in situ from a $\mathrm{Ni}$ (II) salt and 2-mercaptoethanol within a $\beta$-ketoenamine-linked crystalline COF bearing polar water-soluble N/S-containing 2,5-diphenyl-[1,3]-thiazolo[5,4d][1,3]thiazole (DTz, Figure 3) bridges (TpDTz-COF) [25]. The superior photocatalytic HER activity of the TpDTz-COF/Ni-cluster system when compared with its counterpart bearing surface-bonded Pt NPs as co-catalyst is assigned to an effective blocking of charge recombination by the physiosorbed co-catalyst [25].

The presence of co-catalyst stabilizing groups on the COF's structure has been shown to be relevant in some specific cases and is a strategy that can be further exploited to fine-tune both the morphology and intrinsic kinetics of the co-catalyst and the COF/cocatalyst interface (in relation to charge transfer and recombination processes). This is, for instance, the case for the crystalline CTF-COF containing bipyridine bridges (CTF-HC6) for which both Pd and Pt NPs were grown at its surface [59]. Pd, with better affinity 
than Pt for the pyridylic $\mathrm{N}$ atoms of the COF bridges, yielded smaller NPs ( $2.9 \mathrm{~nm}$ vs. $4.3 \mathrm{~nm}$ in the case of $\mathrm{Pt}$ ) at the COF surface, which resulted in superior photocatalytic HER activity (11.1 times higher for Pd than for Pt under the same experimental conditions). In a related but more recent strategy, the introduction of covalently bonded single co-catalyst atoms into the COF's structure through synthetic covalent functionalization (generating the so-called metal-coordinated COFS, M-COFS) has also shown potential to improve charge separation and avoid recombination events. One example can be found in a binuclear $\mathrm{Cu}$-containing COF, Cu-salphen-HDCOF [33]. The imine-linked salphen-HDCOF has two perfect vacancies for the binding of two $\mathrm{Cu}(\mathrm{II})$ ions in a N,N,O,O-tetradentate Schiff base environment. Thus, reaction of salphen-HDCOF with $\mathrm{Cu}(\mathrm{II})$ acetate leads to the formation of $\mathrm{Cu}$-salphen-HDCOF, which, after exfoliation into narrow nanosheets, acts as the cocatalyst during the photocatalytic HER. Another example can be found in the Co-modified hydrazone-based NUS-55 COF obtained by reaction of the COF with $\left[\mathrm{Co}(\mathrm{bpy})_{3}\right] \mathrm{Cl}_{2}[34]$, with a moderate photocatalytic HER activity $\left(2.5 \mathrm{mmol} \mathrm{H}_{2} \cdot \mathrm{g}^{-1} \cdot \mathrm{h}^{-1}\right)$.

Overall, together with the general challenge of finding alternatives to precious metals as co-catalysts in the COF-based photocatalytic HER while keeping the overall performance, further research on the engineering of appropriate $\mathrm{COF} / \mathrm{co}$-catalyst interfaces is required. The combination of COF post-functionalization strategies with the tunability of both NPs through surface functionalization with stabilizing agents and molecular/single-atom catalysts through ligand design provides a myriad of combinations to rationally design better interfaces with optimized charge-transfer and separation properties.

\section{Final Remarks}

Regardless of all the aspects described above, at least four other issues that cannot be disregarded at all should be tackled soon. The first is the development of cheaper and cleaner synthetic methods for the obtention of COFs. Despite the efforts made in this aspect [60], there is still much room for improvement. The second, which is related to the first, is the advancement in larger synthetic scales to make COFs economically viable for practical applications [60]. The third is the deposition of COF-based thin-films for their direct use in (photo)electrodes. In addition, deactivation pathways due to co-catalyst loss or deactivation, photochemical decomposition, or other physicochemical processes that could also take place have been almost not studied so far. In our opinion, characterizing the fate of the photocatalyst is an unambiguous source of valuable information that is mandatory for designing future COF-mediated HER photocatalytic systems suitable to be incorporated in engineered solar fuel cells.

Another very urgent issue to be resolved, which is common to all solar fuel fields, is to define an objective way to properly compare the photocatalytic HER activity of COF-based systems. Until now, the hydrogen production rate has been expressed as mmol of hydrogen produced per hour and per gram of photocatalyst. However, this is somehow misleading, because the photocatalytic activity does not necessarily depend linearly on the mass of the catalyst. Thus, it would be more reliable to compare photocatalytic activity data in terms of solar-to-hydrogen (STH) efficiency, that is, the number of photons that are effectively used in the formation of hydrogen. This STH efficiency should be measured after defining a reference reactor setup under some standardized conditions for the light source (monochromatic vs. white light), power, filters used (if any), and operation temperature, whereas the other parameters, such as solvent (ideally water to aqueous mixtures) and $\mathrm{pH}$, strongly dependent on each particular system, should thus be clearly specified. Analogously, the $A Q E$ values reported so far cannot be fully comparable between different COFs either, since they have not always been measured using the same protocol.

All in all, this review shows the great possibilities of COFs for their applicability in photocatalytic processes. A new myriad of photocatalytic reduction and oxidation processes still awaits, and the great variety of diameters of their pores can be employed for allocating several types of hosts that can act as co-catalysts in these reactions. We are fully 
confident that very exciting new applications of new hybrid inorganic/COF systems will be seen in the coming years.

Author Contributions: N.R. and R.B. carried out the information search and wrote a first draft of the manuscript, and L.F., J.G.-A. and X.S. proposed comparative discussions and modified parts of the manuscript. Frequent meetings between the authors helped to analyze and organize the findings until the final manuscript was obtained. All authors have read and agreed to the published version of the manuscript.

Funding: This research was funded by the Spanish Ministry of Science, Innovation and Universities through the project PID2019-104171RB-I00. L.F. is indebted to the Ramón y Cajal Program (RYC2018025394-I Fellowship) and to the Royal Society of Chemistry (R20-8077 Research Fund).

Conflicts of Interest: The authors declare no conflict of interest.

\section{Abbreviations}

\begin{tabular}{|c|c|}
\hline A & acceptor \\
\hline AA & ascorbic acid \\
\hline Ant & anthracene \\
\hline $\mathrm{AQE}$ & apparent quantum efficiency \\
\hline APTES & 3-aminopropyltriethoxysilane \\
\hline BDBA & benzenediboronic acid \\
\hline BDDA & 4,4'-(buta-1,3-diyne-1,4-diyl)dianiline \\
\hline BET & Brunauer-Emmett-Teller \\
\hline Bpy & 2,2'-bipyridine \\
\hline BPDC & 2,2'-bipyridine-5,5'-dicarbohydrazine \\
\hline BT & benzothiadiazole \\
\hline СВ & conduction band \\
\hline $\mathrm{COF}$ & covalent organic framework \\
\hline CCP-Th & bithiophene-bridged C-linked conjugated polyn \\
\hline CTF & covalent triazine framework \\
\hline $\mathrm{D}$ & donor \\
\hline DCTMP & 3,5-dicyano-2,4,6-trimethylpyridine \\
\hline DEA & diethylamine \\
\hline DFP & 2,6-diformylphenol \\
\hline DFPTP & 4,4"-diformyl-p-terphenyl \\
\hline DTz & 2,5-diphenyl-[1,3]-thiazolo[5,4-d][1,3]thiazole \\
\hline EDDA & 4,4'-(ethyne-1,2-diyl)dianiline \\
\hline ERDN & 3-ethylrhodanine \\
\hline FS & fused sulfone \\
\hline GCNS & graphitic carbon nitride nanosheets \\
\hline НАТР & 2,3,6,7,10,11-hexaaminotriphenylene \\
\hline HER & hydrogen evolution reaction \\
\hline HOMO & highest occupied molecular orbital \\
\hline HНTP & hexahydroxytriphenylene \\
\hline HUST & Huazhong University of Science and Technology \\
\hline LUMO & lowest unoccupied molecular orbital \\
\hline $\mathrm{M}-\mathrm{COF}$ & metal coordinated $\mathrm{COF}$ \\
\hline MOF & metal organic framework \\
\hline $\mathrm{NP}$ & nanoparticle \\
\hline PDAN & 1,4-phenylenediacetonitrile \\
\hline POP & porous organic polymer \\
\hline PTP & phenyl tripyridyl \\
\hline PVP & polyvinylpyrrolidone \\
\hline Рa-1 & p-phenylenediamine \\
\hline Рa-2 & 2,5-dimethyl-p-phenylenediamine \\
\hline Pyr & pyrene \\
\hline
\end{tabular}




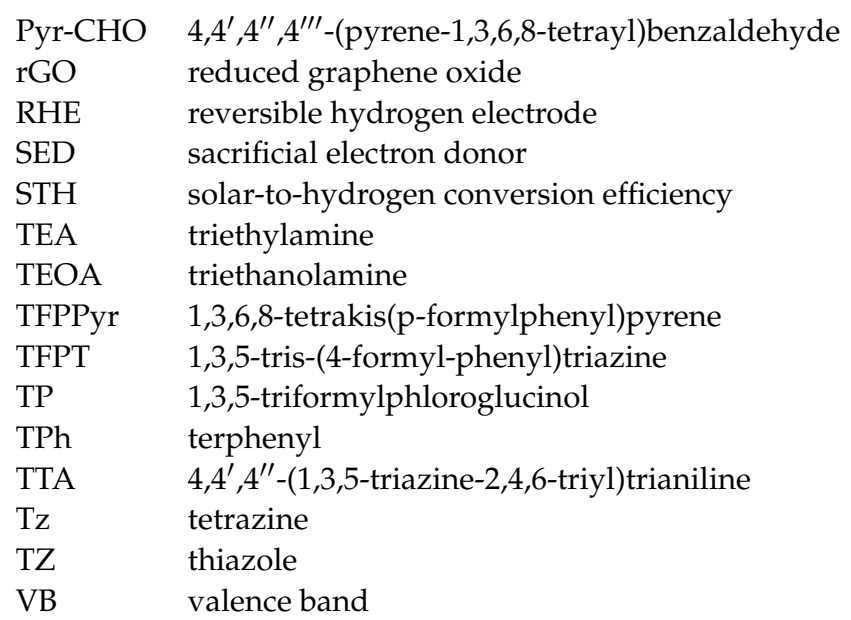

\section{References}

1. Côté, A.P.; Benin, A.I.; Ockwig, N.W.; O’Keeffe, M.; Matzger, A.J.; Yaghi, O.M. Porous, Crystalline, Covalent Organic Frameworks. Science 2005, 310, 1166-1170. [CrossRef] [PubMed]

2. Wang, H.; Wang, H.; Wang, Z.; Tang, L.; Zeng, G.; Xu, P.; Chen, M.; Xiong, T.; Zhou, C.; Li, X.; et al. Covalent Organic Framework Photocatalysts: Structures and Applications. Chem. Soc. Rev. 2020, 49, 4135-4165. [CrossRef] [PubMed]

3. Li, Z.; He, T.; Gong, Y.; Jiang, D. Covalent Organic Frameworks: Pore Design and Interface Engineering. Acc. Chem. Res. 2020, 53, 1672-1685. [CrossRef]

4. $\quad$ Peng, Y.; Li, L.; Zhu, C.; Chen, B.; Zhao, M.; Zhang, Z.; Lai, Z.; Zhang, X.; Tan, C.; Han, Y.; et al. Intramolecular Hydrogen BondingBased Topology Regulation of Two-Dimensional Covalent Organic Frameworks. J. Am. Chem. Soc. 2020, 142, 13162-13169. [CrossRef]

5. Zhao, X.; Pachfule, P.; Li, S.; Langenhahn, T.; Ye, M.; Schlesiger, C.; Praetz, S.; Schmidt, J.; Thomas, A. Macro/Microporous Covalent Organic Frameworks for Efficient Electrocatalysis. J. Am. Chem. Soc. 2019, 141, 6623-6630. [CrossRef]

6. Low, J.; Dai, B.; Tong, T.; Jiang, C.; Yu, J. In Situ Irradiated X-Ray Photoelectron Spectroscopy Investigation on a Direct Z-Scheme $\mathrm{TiO}_{2} /$ CdS Composite Film Photocatalyst. Adv. Mater. 2019, 31, 1802981. [CrossRef] [PubMed]

7. Martin, D.J.; Liu, G.; Moniz, S.J.A.; Bi, Y.; Beale, A.M.; Ye, J.; Tang, J. Efficient Visible Driven Photocatalyst, Silver Phosphate: Performance, Understanding and Perspective. Chem. Soc. Rev. 2015, 44, 7808-7828. [CrossRef] [PubMed]

8. Dong, G.; Zhang, Y.; Pan, Q.; Qiu, J. A Fantastic Graphitic Carbon Nitride (g-C3N4) Material: Electronic Structure, Photocatalytic and Photoelectronic Properties. J. Photochem. Photobiol. C Photochem. Rev. 2014, 20, 33-50. [CrossRef]

9. Stegbauer, L.; Schwinghammer, K.; Lotsch, B.V. A Hydrazone-Based Covalent Organic Framework for Photocatalytic Hydrogen Production. Chem. Sci. 2014, 5, 2789-2793. [CrossRef]

10. Zhang, T.; Xing, G.; Chen, W.; Chen, L. Porous Organic Polymers: A Promising Platform for Efficient Photocatalysis. Mater. Chem. Front. 2020, 4, 332-353. [CrossRef]

11. Jayakumar, J.; Chou, H.H. Recent Advances in Visible-Light-Driven Hydrogen Evolution from Water Using Polymer Photocatalysts. Chem CatChem 2020, 12, 689-704. [CrossRef]

12. Rahman, M.Z.; Kibria, M.G.; Mullins, C.B. Metal-Free Photocatalysts for Hydrogen Evolution. Chem. Soc. Rev. 2020, 49, 1887-1931. [CrossRef]

13. Guo, L.; Jin, S. Stable Covalent Organic Frameworks for Photochemical Applications. ChemPhotoChem 2019, 3, 973-983. [CrossRef]

14. Banerjee, T.; Gottschling, K.; Savasci, G.; Ochsenfeld, C.; Lotsch, B.V. H2 Evolution with Covalent Organic Framework Photocatalysts. ACS Energy Lett. 2018, 3, 400-409. [CrossRef]

15. Banerjee, T.; Podjaski, F.; Kröger, J.; Biswal, B.P.; Lotsch, B.V. Polymer Photocatalysts for Solar-to-Chemical Energy Conversion. Nat. Rev. Mater. 2020, 6. [CrossRef]

16. You, J.; Zhao, Y.; Wang, L.; Bao, W. Recent Developments in the Photocatalytic Applications of Covalent Organic Frameworks: A Review. J. Clean. Prod. 2021, 291, 125822. [CrossRef]

17. Huang, X.; Zhang, Y.-B. Covalent Organic Frameworks for Sunlight-Driven Hydrogen Evolution. Chem. Lett. 2021, 50, 676-686. [CrossRef]

18. Chen, W.; Wang, L.; Mo, D.; He, F.; Wen, Z.; Wu, X.; Xu, H.; Chen, L. Modulating Benzothiadiazole-Based Covalent Organic Frameworks via Halogenation for Enhanced Photocatalytic Water Splitting. Angew. Chem. Int. Ed. 2020, 59, 16902-16909. [CrossRef] [PubMed]

19. Vyas, V.S.; Haase, F.; Stegbauer, L.; Savasci, G.; Podjaski, F.; Ochsenfeld, C.; Lotsch, B.V. A Tunable Azine Covalent Organic Framework Platform for Visible Light-Induced Hydrogen Generation. Nat. Commun. 2015, 6, 8508. [CrossRef]

20. Liu, M.; Huang, Q.; Wang, S.; Li, Z.; Li, B.; Jin, S.; Tan, B. Crystalline Covalent Triazine Frameworks by In Situ Oxidation of Alcohols to Aldehyde Monomers. Angew. Chem. Int. Ed. 2018, 57, 11968-11972. [CrossRef] 
21. Wang, K.; Yang, L.-M.; Wang, X.; Guo, L.; Cheng, G.; Zhang, C.; Jin, S.; Tan, B.; Cooper, A. Covalent Triazine Frameworks via a Low-Temperature Polycondensation Approach. Angew. Chem. Int. Ed. 2017, 56, 14149-14153. [CrossRef] [PubMed]

22. Zhang, S.; Cheng, G.; Guo, L.; Wang, N.; Tan, B.; Jin, S. Strong-Base-Assisted Synthesis of a Crystalline Covalent Triazine Framework with High Hydrophilicity via Benzylamine Monomer for Photocatalytic Water Splitting. Angew. Chem. 2020, 132, 6063-6070. [CrossRef]

23. Pachfule, P.; Acharjya, A.; Roeser, J.; Langenhahn, T.; Schwarze, M.; Schomäcker, R.; Thomas, A.; Schmidt, J. Diacetylene Functionalized Covalent Organic Framework (COF) for Photocatalytic Hydrogen Generation. J. Am. Chem. Soc. 2018, 140, 1423-1427. [CrossRef]

24. Wang, X.; Chen, L.; Chong, S.Y.; Little, M.A.; Wu, Y.; Zhu, W.H.; Clowes, R.; Yan, Y.; Zwijnenburg, M.A.; Sprick, R.S.; et al. Sulfone-Containing Covalent Organic Frameworks for Photocatalytic Hydrogen Evolution from Water. Nat. Chem. 2018, 10, 1180-1189. [CrossRef] [PubMed]

25. Biswal, B.P.; Vignolo-González, H.A.; Banerjee, T.; Grunenberg, L.; Savasci, G.; Gottschling, K.; Nuss, J.; Ochsenfeld, C.; Lotsch, B.V. Sustained Solar H2 Evolution from a Thiazolo[5,4-d]Thiazole-Bridged Covalent Organic Framework and Nickel-Thiolate Cluster in Water. J. Am. Chem. Soc. 2019, 141, 11082-11092. [CrossRef]

26. Jin, E.; Lan, Z.; Jiang, Q.; Geng, K.; Li, G.; Wang, X.; Jiang, D. 2D Sp2 Carbon-Conjugated Covalent Organic Frameworks for Photocatalytic Hydrogen Production from Water. Chem 2019, 5, 1632-1647. [CrossRef]

27. Xu, S.; Sun, H.; Addicoat, M.; Biswal, B.P.; He, F.; Park, S.W.; Paasch, S.; Zhang, T.; Sheng, W.; Brunner, E.; et al. Thiophene-Bridged Donor-Acceptor Sp2-Carbon-Linked 2D Conjugated Polymers as Photocathodes for Water Reduction. Adv. Mater. 2021, 33, 2006274. [CrossRef]

28. Bi, S.; Yang, C.; Zhang, W.; Xu, J.; Liu, L.; Wu, D.; Wang, X.; Han, Y.; Liang, Q.; Zhang, F. Two-Dimensional Semiconducting Covalent Organic Frameworks via Condensation at Arylmethyl Carbon Atoms. Nat. Commun. 2019, 10, 2467. [CrossRef]

29. Huang, W.; Luo, W.; Li, Y. Two-Dimensional Semiconducting Covalent Organic Frameworks for Photocatalytic Solar Fuel Production. Mater. Today 2020, 40, 160-172. [CrossRef]

30. He, T.; Geng, K.; Jiang, D. Engineering Covalent Organic Frameworks for Light-Driven Hydrogen Production from Water. Acs Mater. Lett. 2019, 1, 203-208. [CrossRef]

31. Qian, Z.; Wang, Z.J.; Zhang, K.A.I. Covalent Triazine Frameworks as Emerging Heterogeneous Photocatalysts. Chem. Mater. 2021, 33, 1909-1926. [CrossRef]

32. Ghosh, S.; Nakada, A.; Springer, M.A.; Kawaguchi, T.; Suzuki, K.; Kaji, H.; Baburin, I.; Kuc, A.; Heine, T.; Suzuki, H.; et al. Identification of Prime Factors to Maximize the Photocatalytic Hydrogen Evolution of Covalent Organic Frameworks. J. Am. Chem. Soc. 2020, 142, 9752-9762. [CrossRef]

33. Zang, Y.; Wang, R.; Shao, P.P.; Feng, X.; Wang, S.; Zang, S.Q.; Mak, T.C.W. Prefabricated Covalent Organic Framework Nanosheets with Double Vacancies: Anchoring Cu for Highly Efficient Photocatalytic H2evolution. J. Mater. Chem. A 2020, 8, 25094-25100. [CrossRef]

34. Wang, J.; Zhang, J.; Peh, S.B.; Liu, G.; Kundu, T.; Dong, J.; Ying, Y.; Qian, Y.; Zhao, D. Cobalt-Containing Covalent Organic Frameworks for Visible Light-Driven Hydrogen Evolution. Sci. China Chem. 2020, 63, 192-197. [CrossRef]

35. Mi, Z.; Zhou, T.; Weng, W.; Unruangsri, J.; Hu, K.; Yang, W.; Wang, C.; Zhang, K.A.I.; Guo, J. Covalent Organic Frameworks Enabling Site-Isolation of Viologen-Derived Electron Transfer Mediators for Stable Photocatalytic Hydrogen Evolution. Angew. Chem. Int. Ed. 2021, 60, 9642-9649. [CrossRef] [PubMed]

36. Li, S.; Wu, M.F.; Guo, T.; Zheng, L.L.; Wang, D.; Mu, Y.; Xing, Q.J.; Zou, J.P. Chlorine-Mediated Photocatalytic Hydrogen Production Based on Triazine Covalent Organic Framework. Appl. Catal. B Environ. 2020, 272, 118989. [CrossRef]

37. Haase, F.; Banerjee, T.; Savasci, G.; Ochsenfeld, C.; Lotsch, B.V. Structure-Property-Activity Relationships in a Pyridine Containing Azine-Linked Covalent Organic Framework for Photocatalytic Hydrogen Evolution. Faraday Discuss. 2017, 201, 247-264. [CrossRef] [PubMed]

38. Wang, K.; Jia, Z.; Bai, Y.; Wang, X.; Hodgkiss, S.E.; Chen, L.; Chong, S.Y.; Wang, X.; Yang, H.; Xu, Y.; et al. Synthesis of Stable Thiazole-Linked Covalent Organic Frameworks via a Multicomponent Reaction. J. Am. Chem. Soc. 2020, 142, 11131-11138 [CrossRef] [PubMed]

39. Gao, Z.Z.; Wang, Z.K.; Wei, L.; Yin, G.; Tian, J.; Liu, C.Z.; Wang, H.; Zhang, D.W.; Zhang, Y.B.; Li, X.; et al. Water-Soluble 3D Covalent Organic Framework That Displays an Enhanced Enrichment Effect of Photosensitizers and Catalysts for the Reduction of Protons to H2. ACS Appl. Mater. Interfaces 2020, 12, 1404-1411. [CrossRef] [PubMed]

40. Mo, C.; Yang, M.; Sun, F.; Jian, J.; Zhong, L.; Fang, Z.; Feng, J.; Yu, D. Alkene-Linked Covalent Organic Frameworks Boosting Photocatalytic Hydrogen Evolution by Efficient Charge Separation and Transfer in the Presence of Sacrificial Electron Donors. Adv. Sci. 2020, 7, 1902988. [CrossRef]

41. Chen, R.; Wang, Y.; Ma, Y.; Mal, A.; Gao, X.Y.; Gao, L.; Qiao, L.; Li, X.B.; Wu, L.Z.; Wang, C. Rational Design of Isostructural 2D Porphyrin-Based Covalent Organic Frameworks for Tunable Photocatalytic Hydrogen Evolution. Nat. Commun. 2021, $12,1354$. [CrossRef]

42. Li, L.; Zhu, Y.; Gong, N.; Zhang, W.; Peng, W.; Li, Y.; Zhang, F.; Fan, X. Band-Gap Engineering of Layered Covalent Organic Frameworks via Controllable Exfoliation for Enhanced Visible-Light-Driven Hydrogen Evolution. Int. J. Hydrog. Energy 2020, 45, 2689-2698. [CrossRef] 
43. Wang, H.; Qian, C.; Liu, J.; Zeng, Y.; Wang, D.; Zhou, W.; Gu, L.; Wu, H.; Liu, G.; Zhao, Y. Integrating Suitable Linkage of Covalent Organic Frameworks into Covalently Bridged Inorganic/Organic Hybrids toward Efficient Photocatalysis. J. Am. Chem. Soc. 2020, 142, 4862-4871. [CrossRef] [PubMed]

44. Lin, C.; Han, C.; Gong, L.; Chen, X.; Deng, J.; Qi, D.; Bian, Y.; Wang, K.; Jiang, J. Donor-Acceptor Covalent Organic Framework/g-C 3 N 4 Hybrids for Efficient Visible Light Photocatalytic H 2 Production. Catal. Sci. Technol. 2021, 11, 2616-2621. [CrossRef]

45. Zhang, L.; Zhang, Y.; Huang, X.; Tao, L.; Bi, Y. Direct Observation of Dynamic Interfacial Bonding and Charge Transfer in Metal-Free Photocatalysts for Efficient Hydrogen Evolution. Appl. Catal. B Environ. 2021, 283, 119633. [CrossRef]

46. Chen, Y.; Yang, D.; Shi, B.; Dai, W.; Ren, H.; An, K.; Zhou, Z.; Zhao, Z.; Wang, W.; Jiang, Z. In Situ Construction of HydrazoneLinked COF-Based Core-Shell Hetero-Frameworks for Enhanced Photocatalytic Hydrogen Evolution. J. Mater. Chem. A 2020, 8 , 7724-7732. [CrossRef]

47. Zhang, F.M.; Sheng, J.L.; Yang, Z.D.; Sun, X.J.; Tang, H.L.; Lu, M.; Dong, H.; Shen, F.C.; Liu, J.; Lan, Y.Q. Rational Design of MOF/COF Hybrid Materials for Photocatalytic H2 Evolution in the Presence of Sacrificial Electron Donors. Angew. Chem. Int. Ed. 2018, 57, 12106-12110. [CrossRef] [PubMed]

48. Xu, Z.; Cui, Y.; Guo, B.; Li, H.Y.; Li, H.X. Boosting Visible-Light-Driven H2 Evolution of Covalent Triazine Framework from Water by Modifying Ni(II) Pyrimidine-2-Thiolate Cocatalyst. ChemCatChem 2021, 13, 958-965. [CrossRef]

49. Cheng, Y.J.; Wang, R.; Wang, S.; Xi, X.J.; Ma, L.F.; Zang, S.Q. Encapsulating [Mo3S13]2- Clusters in Cationic Covalent Organic Frameworks: Enhancing Stability and Recyclability by Converting a Homogeneous Photocatalyst to a Heterogeneous Photocatalyst. Chem. Commun. 2018, 54, 13563-13566. [CrossRef] [PubMed]

50. Luo, M.; Yang, Q.; Yang, W.; Wang, J.; He, F.; Liu, K.; Cao, H.; Yan, H. Defects Engineering Leads to Enhanced Photocatalytic H2 Evolution on Graphitic Carbon Nitride-Covalent Organic Framework Nanosheet Composite. Small 2020, 16, 1-8. [CrossRef]

51. Yao, Y.H.; Li, J.; Zhang, H.; Tang, H.L.; Fang, L.; Niu, G.D.; Sun, X.J.; Zhang, F.M. Facile Synthesis of a Covalently Connected RGO-COF Hybrid Material by: In Situ Reaction for Enhanced Visible-Light Induced Photocatalytic H2 Evolution. J. Mater. Chem. A 2020, 8, 8949-8956. [CrossRef]

52. Zhang, Y.P.; Tang, H.L.; Dong, H.; Gao, M.Y.; Li, C.C.; Sun, X.J.; Wei, J.Z.; Qu, Y.; Li, Z.J.; Zhang, F.M. Covalent-Organic Framework Based Z-Scheme Heterostructured Noble-Metal-Free Photocatalysts for Visible-Light-Driven Hydrogen Evolution. J. Mater. Chem. A 2020, 8, 4334-4340. [CrossRef]

53. Gao, M.Y.; Li, C.C.; Tang, H.L.; Sun, X.J.; Dong, H.; Zhang, F.M. Boosting Visible-Light-Driven Hydrogen Evolution of Covalent Organic Frameworks through Compositing with MoS2: A Promising Candidate for Noble-Metal-Free Photocatalysts. J. Mater. Chem. A 2019, 7, 20193-20200. [CrossRef]

54. Thote, J.; Aiyappa, H.B.; Deshpande, A.; Díaz Díaz, D.; Kurungot, S.; Banerjee, R. A Covalent Organic Framework-Cadmium Sulfide Hybrid as a Prototype Photocatalyst for Visible-Light-Driven Hydrogen Production. Chemistry 2014, 20, 15961-15965. [CrossRef]

55. Wang, D.; Zeng, H.; Xiong, X.; Wu, M.F.; Xia, M.; Xie, M.; Zou, J.P.; Luo, S.L. Highly Efficient Charge Transfer in CdS-Covalent Organic Framework Nanocomposites for Stable Photocatalytic Hydrogen Evolution under Visible Light. Sci. Bull. 2020, 65, 113-122. [CrossRef]

56. Li, C.C.; Gao, M.Y.; Sun, X.J.; Tang, H.L.; Dong, H.; Zhang, F.M. Rational Combination of Covalent-Organic Framework and Nano TiO2 by Covalent Bonds to Realize Dramatically Enhanced Photocatalytic Activity. Appl. Catal. B Environ. 2020, $266,118586$. [CrossRef]

57. Ming, J.; Liu, A.; Zhao, J.; Zhang, P.; Huang, H.; Lin, H.; Xu, Z.; Zhang, X.; Wang, X.; Hofkens, J.; et al. Hot $\pi$-Electron Tunneling of Metal-Insulator-COF Nanostructures for Efficient Hydrogen Production. Angew. Chem. Int. Ed. 2019, 58, 18290-18294. [CrossRef]

58. Banerjee, T.; Haase, F.; Savasci, G.; Gottschling, K.; Ochsenfeld, C.; Lotsch, B.V. Single-Site Photocatalytic H2 Evolution from Covalent Organic Frameworks with Molecular Cobaloxime Co-Catalysts. J. Am. Chem. Soc. 2017, 139, 16228-16234. [CrossRef] [PubMed]

59. Liu, M.; Wang, X.; Liu, J.; Wang, K.; Jin, S.; Tan, B. Palladium as a Superior Cocatalyst to Platinum for Hydrogen Evolution Using Covalent Triazine Frameworks as a Support. ACS Appl. Mater. Interfaces 2020, 12, 12774-12782. [CrossRef]

60. Chen, Y.; Li, W.; Wang, X.H.; Gao, R.Z.; Tang, A.N.; Kong, D.M. Green Synthesis of Covalent Organic Frameworks Based on Reaction Media. Mater. Chem. Front. 2021, 5, 1253-1267. [CrossRef] 